\title{
A NEW APPROACH TO CALCULATE MUD INVASION IN RESERVOIRS USING WELL LOGS
}

\author{
Mariléa Ribeiro and Abel Carrasquilla
}

\begin{abstract}
Muds of different compositions are used in the drilling well process, to support the wall of the borehole along with maintenance of pressure, and to remove rock cuttings generated from the geological formations encountered by the drill bit. The drilling mud invades the formations and modifies the zones surrounding the borehole, mainly, in terms of the physical properties of the rocks, such as porosity and permeability. The identification of this formation damage is important for reservoir characterization, and the subsequent well completion, as well as for the analysis of economic viability. Many years ago, Schlumberger developed a method for determining mud invasion diameter using the Tornado Chart. Today, practitioners in the oil industry use the Tornado Chart to present geophysical logs. Improving upon Schlumberger's methodology, Crain used mathematical equations to calculate the mud invasion diameter. In this study, we propose a polynomial mathematical method to determine mud invasion diameter. Our method utilizes the same resistivity well logs, namely dual induction log and dual laterology, though different from that of Schlumberger or Crain methods. The approach developed in this study considers the characteristics of the invasion process while quickly and accurately showing results in the form of a log that can be visualized adjacent to other logs measured in the borehole.
\end{abstract}

Keywords: formation damage, drilling mud invasion, resistivity well logs.

RESUMO. No processo de perfuração de poços são utilizadas diferentes composições de lama com o propósito de suportar a parede do poço, manter a pressão e, ainda, remover os fragmentos de rocha originados pela broca ao atravessar as formações geológicas. A lama de perfuração invade as formações e modifica as zonas circundantes ao poço, sobretudo, em termos das propriedades físicas das rochas, tais como a porosidade e permeabilidade. A identificação deste tipo de dano à formação é importante, principalmente para a caracterização do reservatório, bem como nas atividades posteriores de conclusão do poço e, ainda, na análise de viabilidade econômica. Neste sentido, há muitos anos, a Schlumberger desenvolveu uma maneira de determinar o diâmetro de invasão da lama usando o Gráfico Tornado, que é utilizado até hoje na indústria do petróleo, essencialmente usando perfis geofísicos. Mais tarde, com o objetivo de melhorar a determinação do diâmetro de invasão, Crain usou equações matemáticas para calcular esse valor, fazendo correções na metodologia da Schlumberger. Neste trabalho, por outro lado, propõe-se um método matemático polinomial para determinar o diâmetro de invasão, que é diferente das metodologias desenvolvidas pela Schlumberger e por Crain, mas também utilizando os mesmos perfis resistivos de poços, ou seja, os perfis de indução (DIL) e laterolog (DLL) duplos. Desta forma, o procedimento desenvolvido no presente trabalho mostrou-se rápido e preciso, pois considera melhor as características do processo de invasão, mostrando ainda os resultados sob a forma de um perfil ao lado de outros perfis medidos no poço, resultando, assim, numa visualização mais eficiente.

Palavras-chave: dano à formação, invasão da lama de perfuração, perfis resistivos de poços. 


\section{INTRODUCTION}

The drilling of a well is the most expensive stage in the oil exploration process of the oil industry. This is because of the timeintensive nature of drilling a borehole. Drilling involves the mechanical parts of the rig, rod, and bit, which is cooled by drilling mud. Drilling mud consists of solids, liquids, and gases and is designed to carry debris (i.e. cuttings) up to the surface, in addition to lubricating the bit and stabilizing the wall of the borehole under the exerted hydrostatic pressure (Machado, 2002). This pressure is larger than the formation pressure, and prevents the invasion of hydrocarbons into the well, which can cause accidents in surface facilities. This pressure gradient may cause the mud to advance into the geological formation, causing an invasion that begins at the wall of the well as a mudcake and forms a sealing agent. From the mudcake, the concentration of the particles in the mud decreases with distance inside the reservoir, forming an intermediate zone of the mud filtrate, which is subdivided into invaded and transition zones. After this transition zone, there is a virgin or uninvaded zone, where oil, gas and formation water are located (El-Wazzer \& Ad Haggag, 1999). In the transition zone, an annulus zone can occur, where a displacement or mixture of fluids occurs. This determines the limit of invasion, known as the mud invasion diameter, $D_{i}$ (Fig. 1).

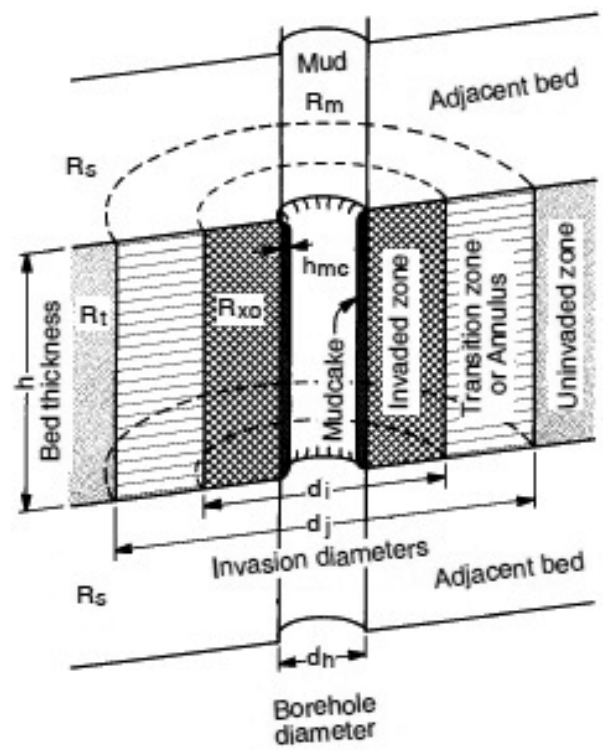

Figure 1 - Logging environment (modified from Anderson, 2001).

After drilling, openhole well logs are performed by descending several tools that record physical or petrophysical parameters such as density, porosity, clay volume, and others. These parameters are part of a set of fundamental information that can be used for petroleum reservoir characterization (Anderson, 2001). One of the parameters is electrical resistivity, which relates to the volumetric characteristics of rocks that comprise the matrix and fluids present in pores thus generating information that defines properties such as saturation and fluid types (Borah et al., 1998).

Currently, the invasion process is mapped by resistivity measurements that are performed using a dual laterolog (DLL) tool, which uses the galvanic phenomenon to drive DC current through the geological media (Baker Hughes, 2002). This system has two sets of seven electrodes in the same tool called LLd (deep) and LLs (shallow), which are considered to be macro logs and are recommended for use with conductive water based mud (Fig. 2). These tools aim to investigate large volumes of rock to obtain virgin zone resistivity $\left(R_{t}\right)$. Alongside these profiles, there are micro-spherical focused (SFL) and micro-cylindrical focused (MCFL) logs, which have shorter distances between electrodes and significantly reduce the required investigation radius. In the SFL and MCFL logs, only the resistivity $R_{x o}$ of the zones close to the borehole wall are recorded (Chen \& Mueller, 1992).

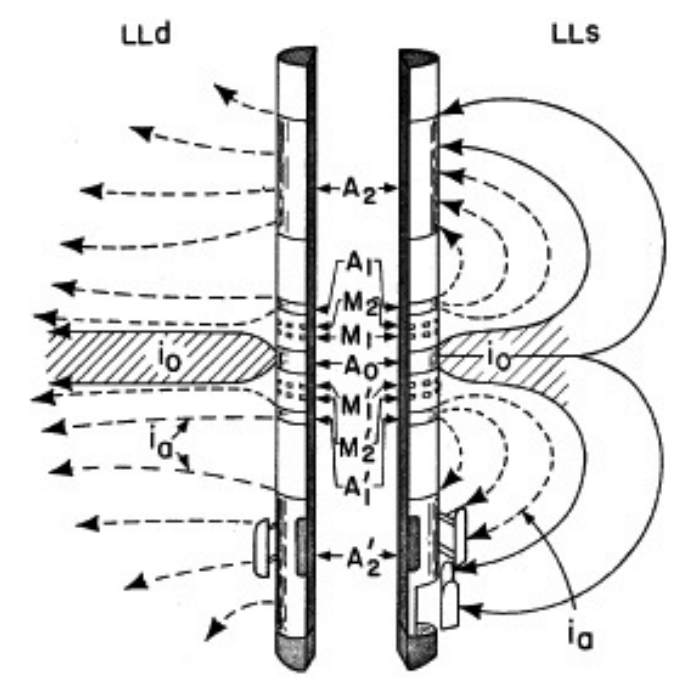

Figure 2 - Schematic diagram of the dual laterolog electrode configuration and current patterns. (The sonde is split for illustrative purposes only; LLS and LLD currents are axisymmetric) $i_{o}$ denotes survey current and $i_{a}$ denotes bucking current. The microSFL is located on the lower $\left(A_{2}\right)$ electrode (modified from Anderson, 2001).

Another log used in the resistivity measurements is the dual induction $\log$ (DIL), which employs the physical principle of inductive electromagnetic coupling between the coils and the geological formations; the DIL minimizes the mud effect existing in galvanic logs. The advantage of using this device is that it does not distort the electric field, penetrating indistinctly in the mudrock environment, particularly when resistive oil-based muds are used (Fig. 3). This combination of sensors allows measuring the resistivity of the virgin zone $\left(R_{I L d}\right)$; however, when the dis- 
tance between them is decreased, the investigation radius is reduced to reach average distances $\left(R_{I L m}\right)$. In addition to these two tools, there is an MCFL tool, which reads more shallow resistivities $\left(R_{M C F L}\right)$ using electrodes. The use of different frequencies in the ILd and ILm tools provides different depths and volumes of investigation, thus allowing the measurement of resistivity of the invaded $\left(R_{x o}\right)$ and virgin $\left(R_{t}\right)$ zones. Furthermore $D_{i}$ can be obtained, which makes it possible to correct the invasion effect (Ellis \& Singer, 2008).

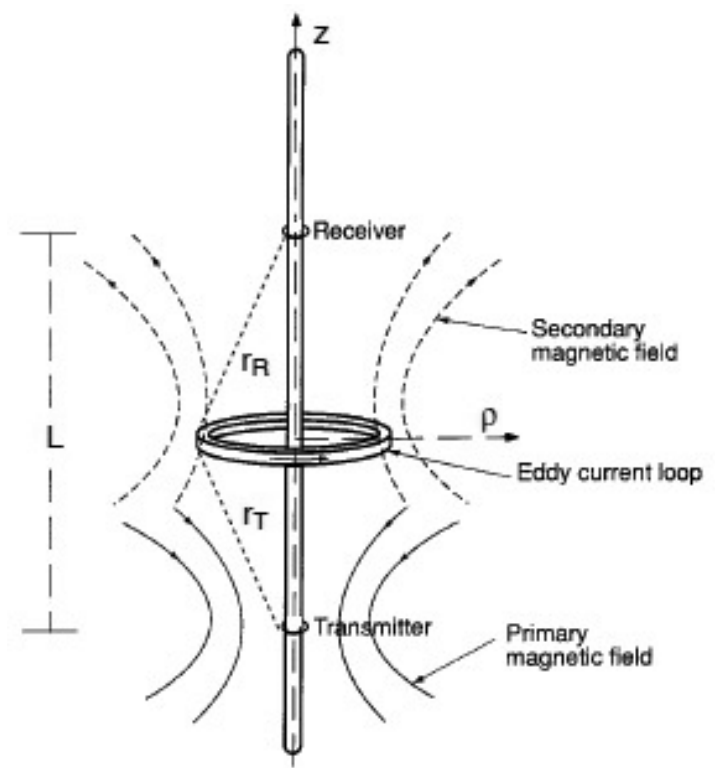

Figure 3 - Basic two-coil induction sonde showing electromagnetic field patterns and the coordinate system used for computing response functions (modified from Anderson, 2001).

Schlumberger (1989) developed the Tornado Chart to correct the effects of invasion on oil producing formations and to estimate $R_{t}$ and $D_{i}$, which measure shallow, medium and deep resistivities. This chart uses the ratios $R_{L L d} / R_{L L s}$ and $R_{L L d} / R_{F S L}$, and $R_{I L m} / R_{I L d}$ and $R_{M C F L} / R_{I L d}$ of the tools DLL and DIL, respectively. These ratios represent the $x$ and $y$ axes, with all its values being read directly on the chart at different intervals. Nowadays, most of the environmental corrections within commercial well log interpretation software modules are based on these charts. There are two basic types of radial resistivity profiles of invasion when resistivities of the invaded zones are considered in a Tornado Chart (Fig. 4). In Figure 4, profile (a) corresponds to the cases where $R_{x o}>R_{t}$, and profile (b) is typical of formations where $R_{x o}<R_{t}$. However, there are variations in points outside the boundaries of the charts, which are considered as Tornado "anomalous", especially when a transition exists between the invaded and virgin zones, known as the annulus. The annulus generally a low resistivity $R_{a n}\left(R_{a n}<R_{t}\right.$ and $\left.R_{a n}<R_{x o}\right)$, because it is a mixture of mud filtrate, formation water, salt and oil. Its location is important because, when it is detected, the presence of oil in the reservoir is certain (Fig. 5). However, different situations may occur when it inverts $R_{a n}<R_{t}$ and $R_{a n}<$ $R_{x o}$, particularly with the use of oil-based muds (Semmelbeck \& Holditch, 1988).

By studying the effects of the invasion of drilling mud, Crain (1984) showed that when the ratios between the shallow and deep resistivities are outside the range of the selected Tornado Chart, it is possible that the chosen chart is not appropriate. Crain (1984) observed, however, that these charts are useful only in the washed area, but show conflicting results in the virgin area, where the oil and annulus zones are located. Worse still, the invasion inside the oil or gas zones usually creates a data set that falls outside the Tornado Chart, and thus, corrections are not made, although they are required.

\section{METHODOLOGY}

It is evident that knowledge of $D_{i}$ is important in reservoir characterization and production operations. Thus, the main objective of our study is to find a direct method to calculate it, registering automatically the damage provoked by mud invasion. In the process, we find a mathematical expression that adequately describes the Tornado Chart and anomalous values as indicated by Crain (1984). The methodology uses DDL and DIL tools, which are used to calculate values of shallow (MCFL or SFL), medium (ILM or LLS), and deep (ILD or LLD) resistivities and allows for obtaining $R_{t}, R_{x o}$, and $D_{i}$ values. Thus, starting from the idea of the Tornado Chart for DLL log, we obtain the following functional relationship:

$$
\frac{R_{t}}{R_{L L d}}=f\left(\log \left[\frac{R_{L L d}}{R_{L L s}}, \frac{R_{L L d}}{R_{S F L}}\right]\right) .
$$

Calling $x=R_{L L d} / R_{L L s}$ and $y=R_{L L d} / R_{S F L}$ and developing Equation (1) in the form of a bicubic polynomial function, we obtain the following:

$$
\frac{R_{t}}{R_{L L d}}=1+D_{i}
$$

where:

$$
D_{i}=a_{1} x+a_{2} x^{2}+a_{3} x y+a_{4} x^{2} y+a_{5} x y^{2}+a_{6} x^{2} y^{2},
$$

is defined as the mud invasion diameter, in which $a_{1} \ldots a_{6}$ are coefficients. 

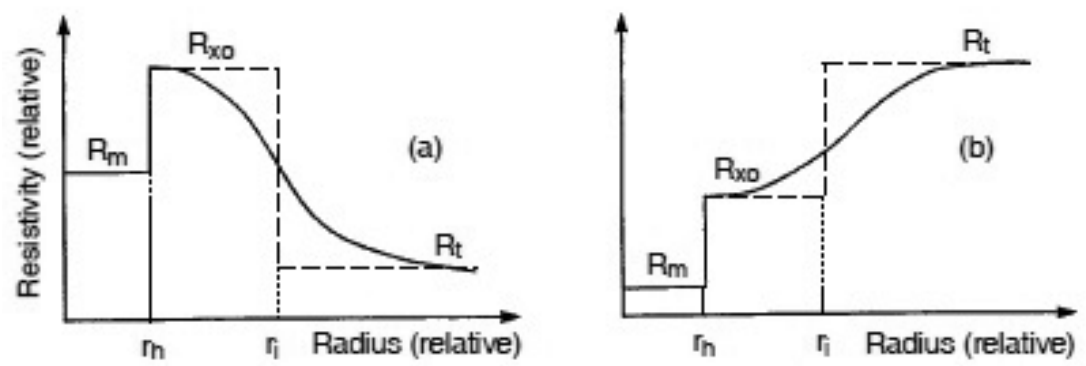

Figure 4 - Radial resistivity profiles encountered in formations drilled with (a) resistive, or (b) conductive mud. Solid lines denote the actual shape of the resistivity profile and dashed lines denote the step profile approximation often used for modeling the invasion effect (modified from Anderson, 2001).
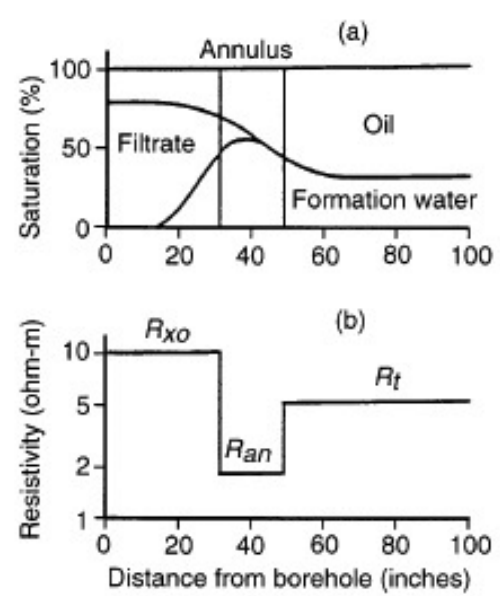

Figure 5 - (a) Saturation and (b) resistivity profiles for a representative example of annulus invasion (modified from Anderson, 2001).

Equation (3) is a two degree polynomial that describes the problem of invasion, because those with greater degrees do not adjust the Tornado Chart. In Equation (2) the number 1 was added to coincide with the Tornado Chart and with the observations of Crain (1984). This author asserts that, obligatorily, the phenomenon of invasion must begin with values exceeding one on a logarithmic scale, defining the workspace with physical parameters as positive and making the mud invasion diameter zero at the time when $x$ is equal to zero. With the objective of obtaining the coefficients of Equation (3), the problem is organized in the following matrix form:

$$
\left[\begin{array}{c}
\left(\frac{R_{t}}{R_{L L d}}\right)_{1} \\
\left(\frac{R_{t}}{R_{L L d}}\right)_{2} \\
\vdots \\
\left(\frac{R_{t}}{R_{L L d}}\right)_{3}
\end{array}\right]=\left[\begin{array}{ccccc}
1 & x_{1} & x_{1}^{2} & y_{1} & y_{1}^{2} \\
1 & x_{2} & x_{2}^{2} & y_{2} & y_{2}^{2} \\
\vdots & \vdots & \vdots & \vdots & \vdots \\
1 & x_{6} & x_{6}^{2} & y_{6} & y_{6}^{2}
\end{array}\right] *\left[\begin{array}{c}
a_{1} \\
a_{2} \\
a_{3} \\
a_{4} \\
a_{5} \\
a_{6}
\end{array}\right]
$$

which, in short, may be expressed in the following linear system:

$$
[S]=[A] *[P],
$$

where

$[S]=$ vector defined by the values of the logs,

$[A]=$ matrix defined by the coordinates $x$ and $y$ of the polynomial, and

$[P]=$ coefficient vector.

$P$ can be solved for this system in the following form:

$$
[P]=[A]^{-1} *[S],
$$

an expression easily solved to calculate $A^{-1}$, which was calculated by the pseudo-inverse function of Moore-Penrose (MAT$L A B, 2012)$.

To obtain $R_{t}, R_{x o}$ and $D_{i}$ values in the form of logs along the well, we developed an algorithm to calculate those parameters using the MATLAB (2012) code. This program considers the mineralogical composition and fluids present in the layers, calculating gamma rays (GR), resistivity (DLL and DIL), density (RHOB), neutron (NPHI) and transit time (Vp and Vs) logs. For a practical purposes, if we know the $x$ and $y$ axes in the Tornado Chart, it is possible to calculate the values of $R_{t} / R_{L L d}, R_{x o} / R_{L L d}$ and $D_{i}$. The previous algorithm perfectly describes all values of the Tornado Chart, for both DLL and DIL tools, and values that are outside the envelope of these charts. On the other hand, the same procedure can be adopted for the DIL log, considering $R_{t} / R_{I L d}$ on the left side of Equation (1), with $x=R_{I L m} / R_{I L d}$ and $y=R_{M S F L} / R_{L L d}$.

\section{RESULTS}

First the proposed methodology was used with synthetic data derivatives from a theoretical model of horizontal layers (Crain, 1984). A simplified model of three layers was used, which facilitates the input of the mineralogical composition of an oil reser- 
voir and its subsequent analysis (Fig. 6). The first and third layers are formed by impermeable shale containing interstitial water and common shale mineral constituents. The second layer, however, comprises sandstone that has a diverse mineralogical composition (quartz, calcite, dolomite, illite, kaolinite and montmorillonite); the the invasion process occurs in the layer (Table 1). In Figure 7, is observed the GR log clearly separates the shale and sandstone layers. The ILD tool does not show significant differences for $R_{I L m}$ and $R_{I L d}$ because of the conductivity of the mud be very conductive, which limits the decay of the electromagnetic energy that cannot unable to penetrate into the formation. The DLL tool, on the other hand, clearly reads the values of $R_{S F L}, R_{L L s}$ and $R_{L L d}$ resistivities, and can be used to detect the presence of hydrocarbons in the reservoir. When comparing our results while calculating the mud invasion radius $R_{i}\left(R_{i}=D_{i} / 2\right)$ within the reservoir, we verified that our LLd results are nearly equal to those of Crain (1984); however Tornado Chart LLd over estimates mud invasion radius relative to Crain (1984) and our results. In the case of ILd, our results underestimate the mud invasion radius relative to those of Crain (1984), with any record to Tornado Chart ILd.

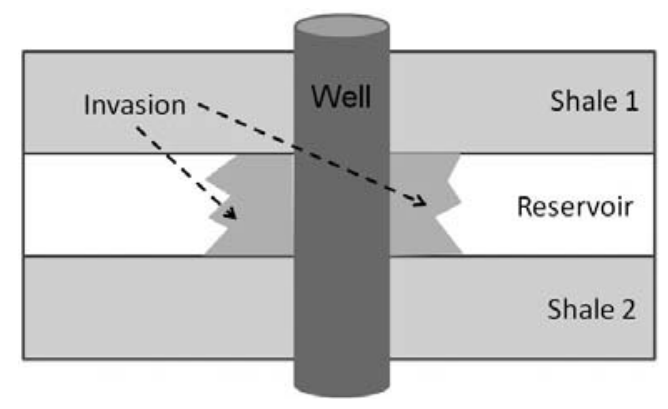

Figure 6 - Model of reservoir with three layers.

Table 1 - Lithology of the model shown in Figure 6.

\begin{tabular}{|c|c|c|c|}
\hline Lithology & Shale 1 & Reservoir & Shale 2 \\
\hline Quartz & 0.20 & 0.10 & 0.20 \\
\hline Calcite & 0.05 & 0.30 & 0.05 \\
\hline Dolomite & 0.00 & 0.05 & 0.05 \\
\hline Illite & 0.25 & 0.05 & 0.20 \\
\hline Kaolinite & 0.15 & 0.02 & 0.15 \\
\hline Montmorilonite & 0.15 & 0.05 & 0.15 \\
\hline Water & 0.20 & 0.02 & 0.20 \\
\hline Oil & 0.00 & 0.40 & 0.00 \\
\hline Gas & 0.00 & 0.01 & 0.00 \\
\hline Total & 1.00 & 1.00 & 1.00 \\
\hline \multicolumn{4}{|c|}{$R_{m f}=0.198$ ohm.m; $R_{m}=0.088$ ohm.m } \\
\hline
\end{tabular}

To apply our technique to real data, we selected an example from Ellis \& Singer (2008, Chapter 5, page 111), which shows typical logs for a DLL tool in a hypothetic reservoir, with $R_{S F L}, R_{L L s}$ and $R_{L L d}$ resistivity values. For the studied depth (36 ft), we obtain the following values: $R_{L L d}=2,000 \mathrm{ohm} \cdot \mathrm{m}$, $R_{L L s}=1,200$ ohm.m and $R_{S F L}=70$ ohm.m (track 1, Fig. 8). When we plot the values of $R_{L L d} / R_{L L s}$ and $R_{L L d} / R_{S F L}$ ratios for all the logs on the Tornado Chart (Fig. 9), we observe that a large number of points are outside the chart, confirming Crain's (1984) affirmations. In that example, the GR $\log$ (not shown in this article) indicates low values; in other words, it is a clean zone, a sandy reservoir of moderate porosity with aquifer and hydrocarbon zones. In this case, the aquifer appears in the bottom part of the curve, in this case with low resistivity values and no separation between $R_{S F L}$ and $R_{I L d}$. The zone of hydrocarbons is given by high resistivity values in the curve above a depth $68 \mathrm{ft}$ depth, but the values are high in the water zone $20 \mathrm{ft}$ below, which indicates a small amount of hydrocarbons or a change in porosity. For this example, the corrections of mud invasion with the Tornado Chart, having the values of $R_{x o}, R_{t}$ and $D_{i}$, can be calculated utilizing the logs $R_{I L d}, R_{I L s}$ and $R_{S F L}$, considering that this last read corresponds to $R_{x o}$ values. In Figure 9, the following is observed at a depth of $36 \mathrm{ft}$ :

$$
\frac{R_{L L d}}{R_{L L s}}=2, \quad \text { and } \quad \frac{R_{L L d}}{R_{S F L}}=30,
$$

which indicates a moderate invasion. In the utilized Tornado Chart (dual laterolog $-R_{x o}$ device, $R_{x o} / R_{m}=50$ ), the intersection of the two ratios of Equation (7) indicates the following relationship:

$$
\frac{R_{L}}{R_{L L d}}=1.28, \quad \text { and } \quad \frac{R_{t}}{R_{x o}}=40 .
$$

In the same Tornado Chart the mud invasion diameter is observed to be $30^{\prime \prime}(0.762 \mathrm{~m})$. In the lower zone (between 48 and $68 \mathrm{ft}$ ) the readings of $R_{L L s}$ and $R_{L L d}$ overlap, indicating a small invasion for which correction is not necessary. In Figure 8, we can observe an $R_{t}$ value (track 2) of 2,000 ohm.m for the studied depth, which coincides with the Ellis \& Singer (2008) value $\left(R t=1.28 R_{L L d}\right)$. In the last track, the mud invasion diameter (red color) is very close to the value calculated by the Crain (1984) algorithm.

In the case of the induction log, we selected an example of Engler (2011), for a depth of $30 \mathrm{~m}$, with the following values: $R_{I L d}=10 \mathrm{ohm} . \mathrm{m}, R_{I L m}=14 \mathrm{ohm} . \mathrm{m}$ and $R_{M C F L}=$ 90 ohm.m (Fig. 10). When we plotted the values of $R_{M C F L} /$ $R_{I L d}$ and $R_{I L m} / R_{I L d}$ ratios for all the logs on the Tornado 

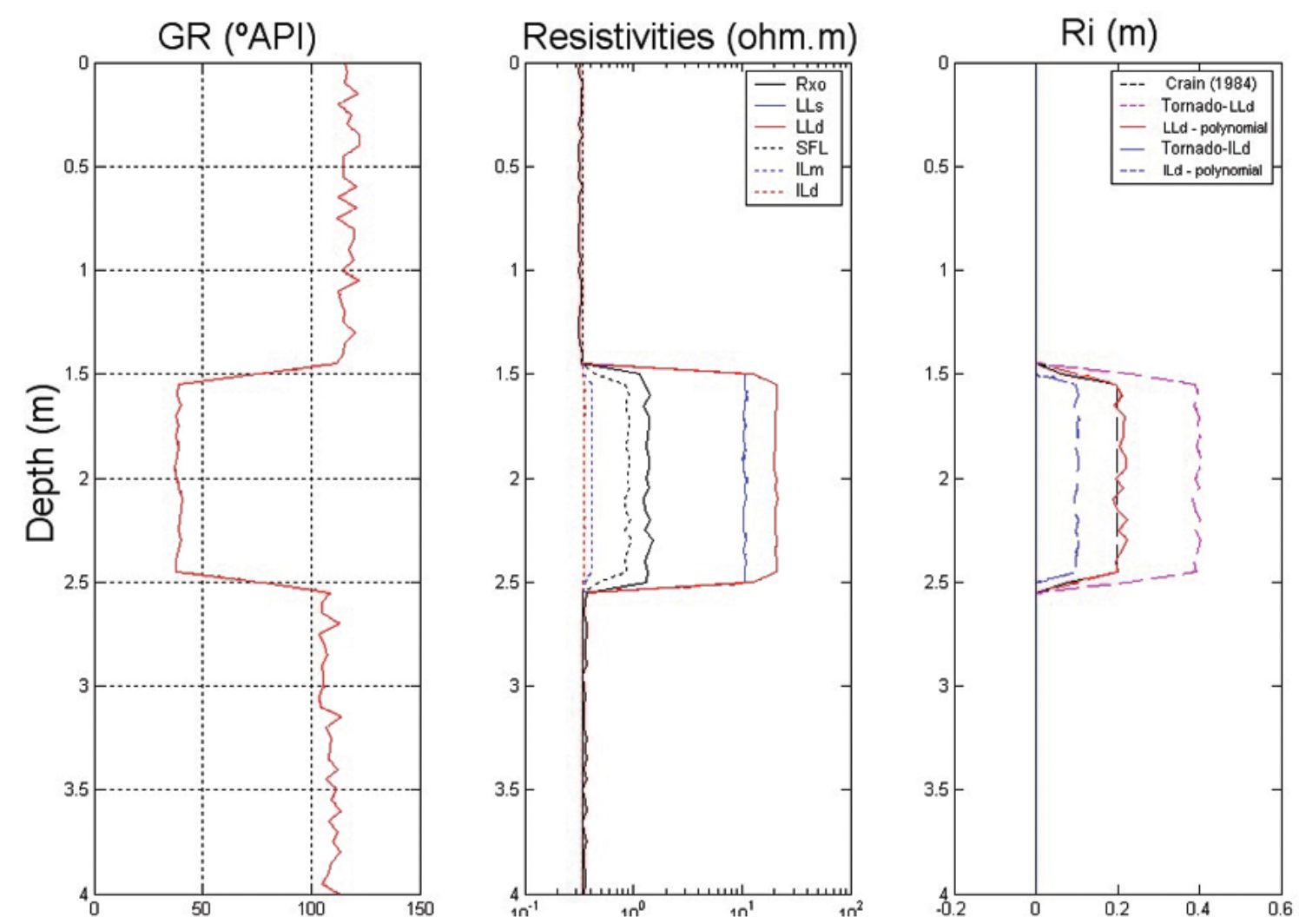

Figure 7 - Invasion profile for model shown in Figure 6.
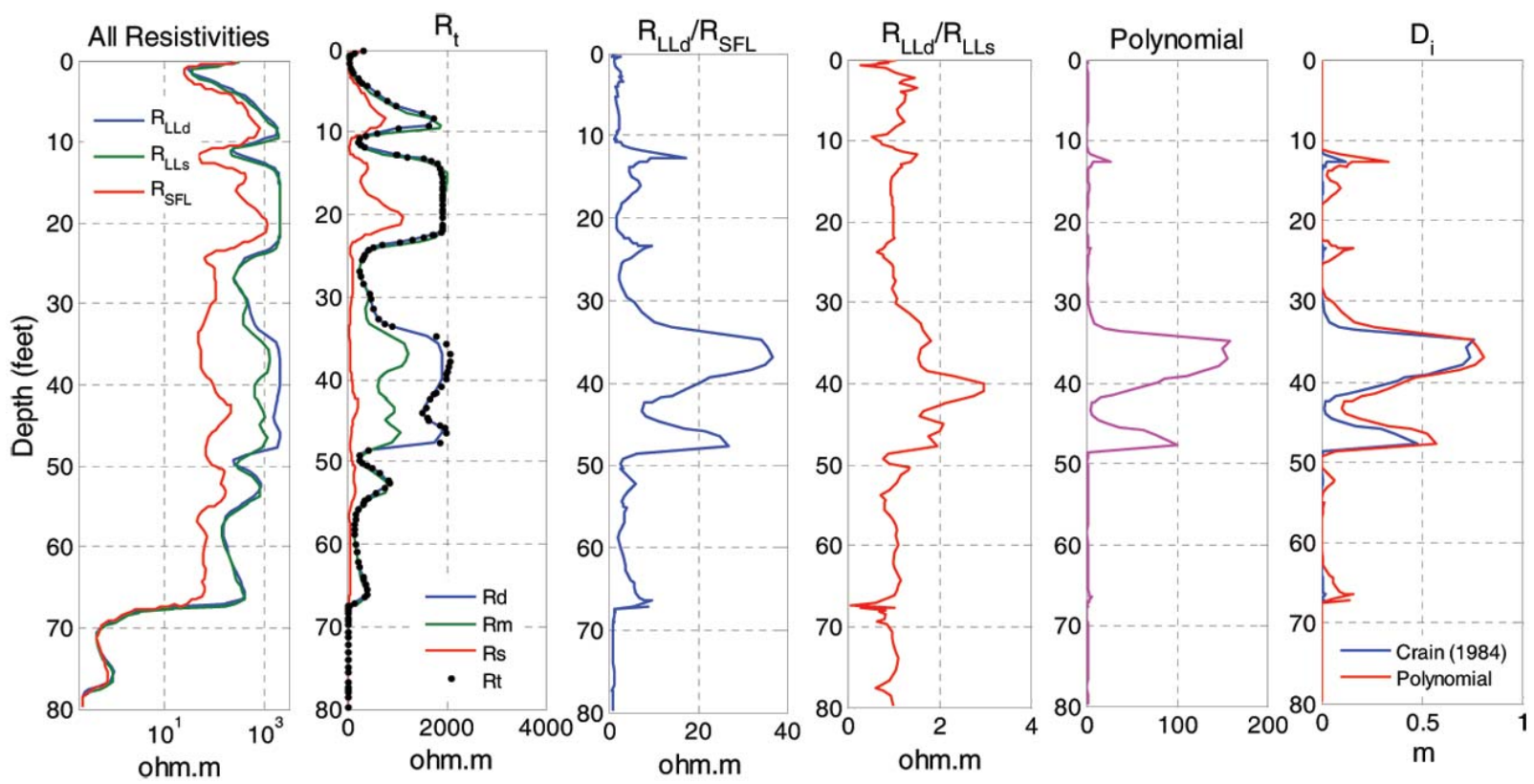

Figure 8 - Results obtained for laterolog. 


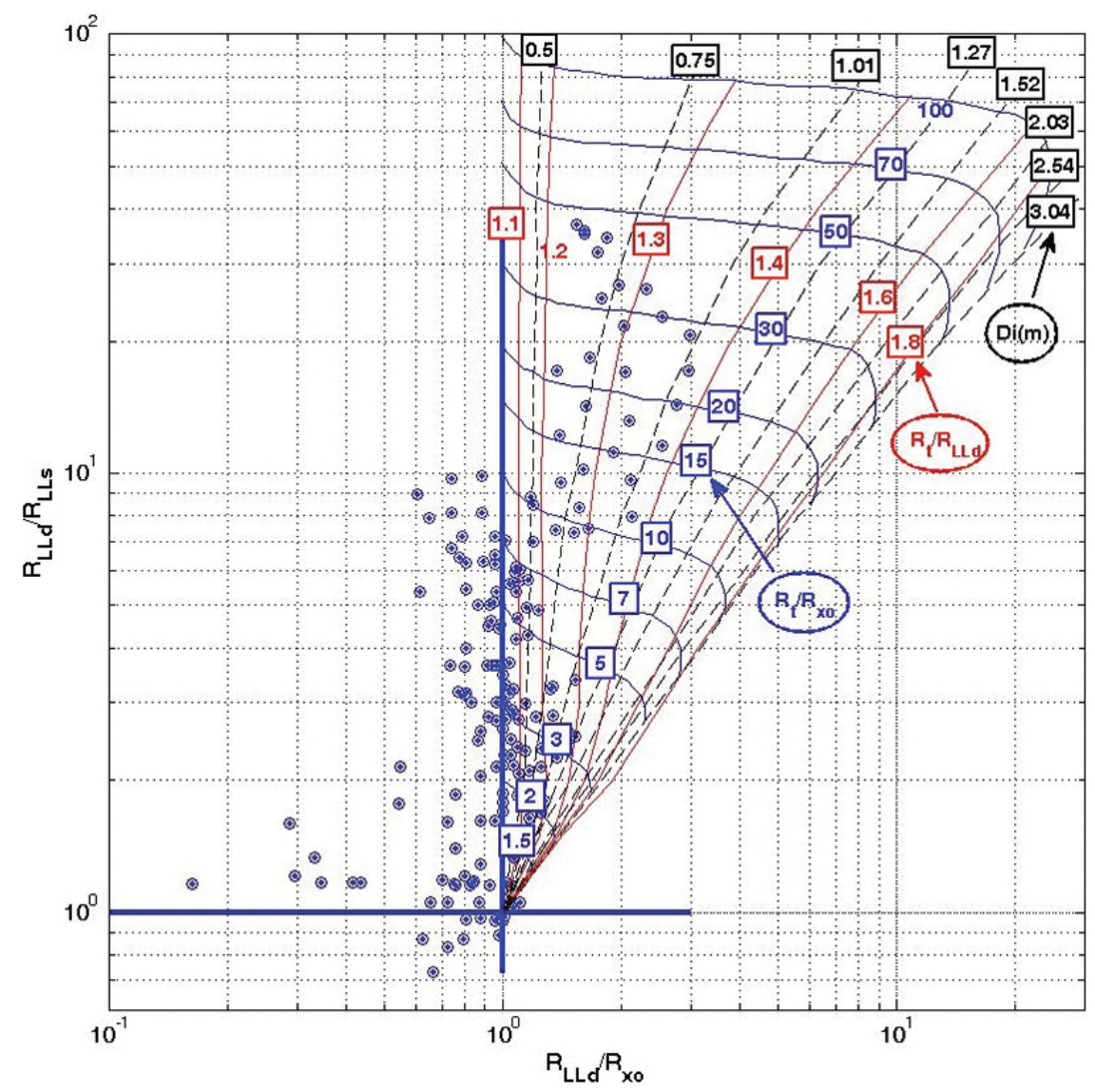

Figure 9 - Tornado Chart for laterolog.

Chart, we observed again that there are points outside the envelope (Fig. 11). In the studied depth, we observed the following values:

$$
\frac{R_{M C F L}}{R_{I L d}}=9, \quad \text { and } \quad \frac{R_{I L m}}{R_{I L d}}=1.4 .
$$

Starting with the Tornado Chart (induction, $R_{x o} / R_{m}=20$ ), we obtain the following:

$$
\frac{R_{t}}{R_{I L d}}=0.89, \quad \text { and } \quad \frac{R_{x o}}{R_{t}}=14
$$

which result in

$$
\begin{gathered}
R_{t}=8.9 \mathrm{ohm} \cdot \mathrm{m}, R_{x o}=144 \mathrm{ohm} \cdot \mathrm{m} \\
\text { and } D_{i}=1.14 \mathrm{~m} .
\end{gathered}
$$

In Figure 11 we can observe that our results for $R_{t}$ and $D_{i}$ coincide with those presented in Equation (11) by Engler (2011) and Crain (1984) algorithm.

\section{CONCLUSIONS}

Charts and algorithms used for environmental corrections of geophysical logging tools have been available for a long time; however, they are based on simple invasion concepts that utilize timeconsuming graphical processes to calculate mud invasion diameter. Thus, the sophistication of modern tools is not accompanied by the best algorithms for environmental correction of logs. It is concluded that these can, probably, never be completely eliminated, but by a combination of various tool responses and forward modeling a better solution can be achieved, avoiding erroneous interpretations. Because of such factors, in our study we developed an algorithm for automatically determining $R_{x o}, R_{t}$ and $D_{i}$, which is based on utilization of a bicubic polynomial function that calculates these parameters. The algorithm begins with resistivity measured using DLL and DIL tools, and the solves a linear system of equations through an inversion process. The algorithm was implemented in MATLAB code and validated with synthetic models and real data logs from the literature. In conclusion, the results presented are consistent, with a small error, indicating that 

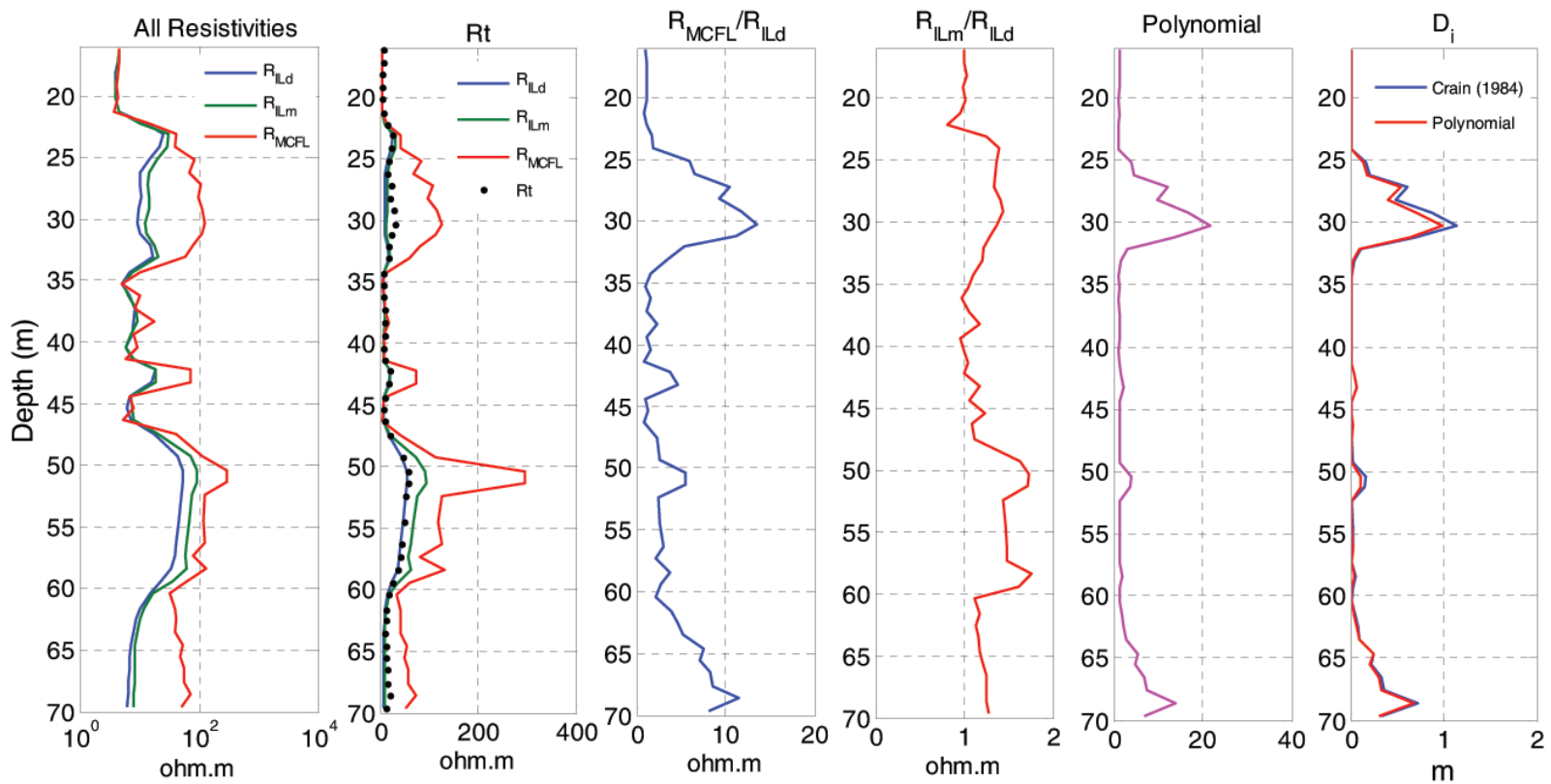

Figure 10 - Results obtained for induction log.

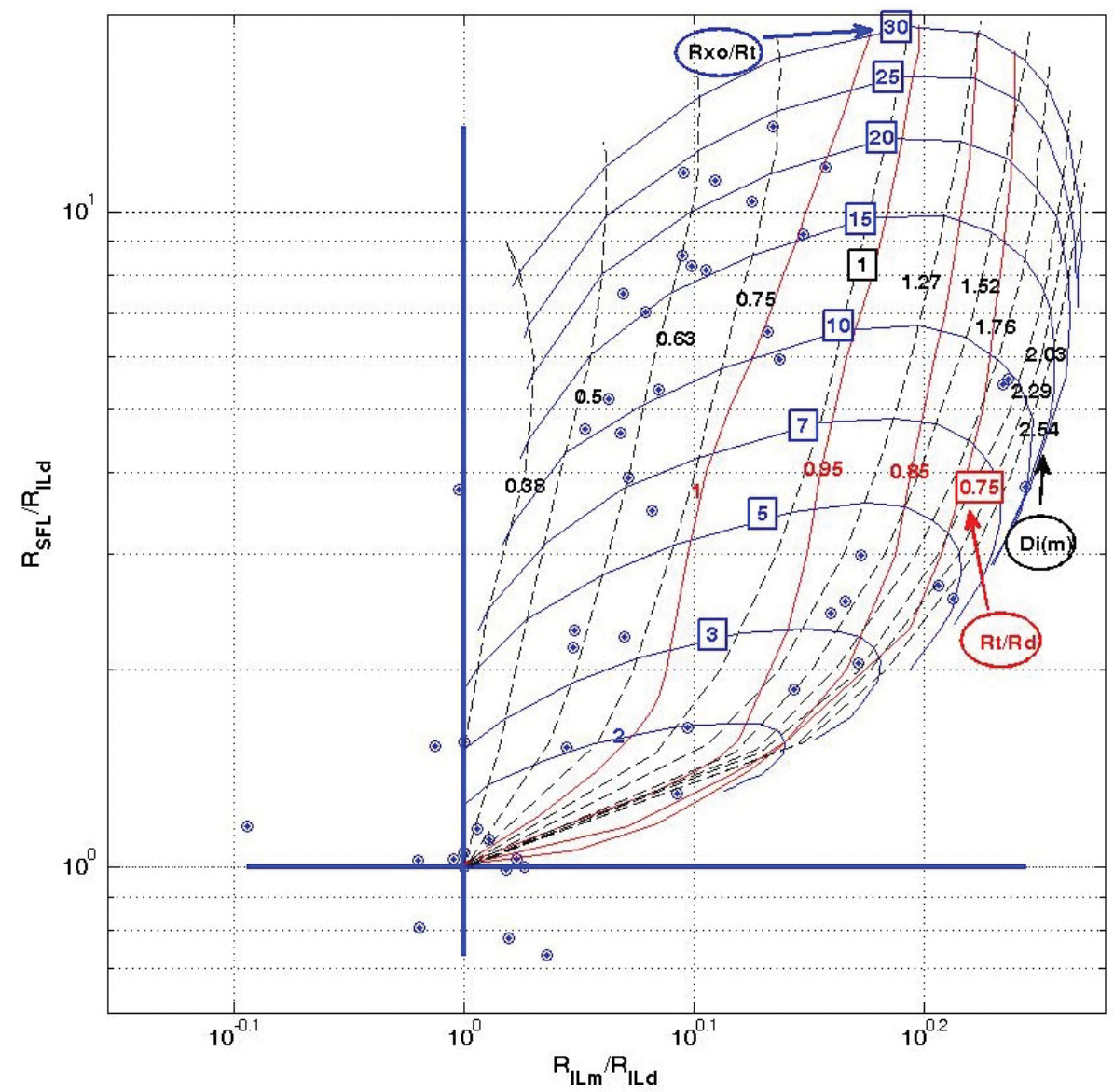

Figure 11 - Tornado Chart for induction. 
our process is automatic, fast, efficient and accurate. Moreover, mud invasion diameter is shown in the form of one log that can be juxtaposed against the other well logs. This facilitates visual recognition of the extent of the invasion of drilling mud into the reservoirs.

\section{ACKNOWLEDGMENTS}

The authors acknowledge the financial and computing infrastructure support provide by Petrobras and LENEP, respectively. Furthermore, this article is dedicated Jadir da Silva (in memoriam) for his eternal friendship.

\section{REFERENCES}

ANDERSON BI. 2001. Modeling and inversion methods for the interpretation of resistivity logging tool response. Western Connecticut State University, USA, $386 \mathrm{pp}$.

BAKER HUGHES. 2002. Introduction to wireline log analysis. Baker Atlas, $312 \mathrm{pp}$.

BORAH N, MALLICK R, CHOUDHURI B \& RATHORES Y. 1998. Mud filtrate invasion profile - Its influence on wireline logs and hydrocarbon producibility: a case study. In: SPE India Oil and Gas Conference and Exhibition, 17-19 February, New Delhi, India. SPE 39510-MS. 15 pp.
CHEN S \& MUELLER T. 1992. A simple approach to mud-invasion correction for dual laterolog resistivities. In: Permian Basin Oil and Gas Recovery Conference, 18-20 March, Midland, Texas. SEP 23962. 9 pp.

CRAIN E. 1984. Crain's Petrophysical Handbook, Online Shareware Petrophysics Training and Reference Manual. Available on:

<http://www.spec2000.net/01-index.htm>. Access on: Aug. 09, 2011.

ELLIS D \& SINGER J. 2008. Well logging for earth scientist. Springer, Dordrecht, The Netherlands. 699 pp.

EL-WAZEER F \& HAGGAG M. 1999. Formation evaluation masked by mud invasion. In: Middle East Oil Show and Conference, 20-23 February, Bahrain, SPE 53152. 6 pp.

ENGLER T. 2011. Lecture notes for PET 370. Chapter 8: Induction Logs. Resistivity Logs: invasion correction example.

MACHADO J. 2002. Reologia e escoamento de fluidos - ênfase na indústria do petróleo. Interciência, Rio de Janeiro, 257 pp.

MATLAB. 2012. User's manual. 214 pp.

SCHLUMBERGER. 1989. Log Interpretation Principles/Applications. Educational Services, Houston. 230 pp.

SEMMELBECK M \& HOLDITCH S. 1988. The effects of mud-filtrate invasion on the interpretation of induction logs. SPE Formation Evaluation. SPE 14491-PA. 386-392.

\section{NOTES ABOUT THE AUTHORS}

Mariléa Gomes dos Santos Ribeiro received a B.Sc. in Electrical Engineering from Universidade Santa Úrsula (1995), a M.Sc. (2007) and a D.Sc. (2013) in Reservoir Engineering and Exploration from Universidade Estadual do Norte Fluminense. Specialist in well logging and petrophysical, presently is visiting researcher and professor of Geophysics Laboratory at Universidade Federal do Rio de Janeiro-UFRJ, Brazil.

Antonio Abel Gonzalez Carrasquilla received a B.Sc. in Chemistry from Universidad Nacional de Panamá (1979), a M.Sc. (1984) and a D.Sc. (1993) in Geophysics from Universidade Federal do Pará. Specialist in surface and borehole electromagnetic methods for natural resources prospecting, mainly groundwater and oil. Presently is Full Professor of the Petroleum Engineering and Exploration Laboratory (LENEP) at Universidade Estadual do Norte Fluminense-UENF, Brazil. 